\title{
Nasopharyngeal isolates and their clinical impact on young children with asthma: a pilot study
}

This article was published in the following Dove Press journal: Journal of Asthma and Allergy

\author{
Ahmed R Alsuwaidi' \\ Alia M Alkalbani \\ Afaf Alblooshi' \\ Junu George' \\ Ghaya Albadi' \\ Salwa $\mathrm{M} \mathrm{Kamal}^{3}$ \\ Hassib Narchi' \\ Abdul-Kader Souid' \\ 'Department of Pediatrics, College \\ of Medicine and Health Sciences, \\ United Arab Emirates University, Al \\ Ain, United Arab Emirates; ${ }^{2}$ Tawam \\ Hospital, Abu Dhabi Health Services \\ Company (SEHA), Al Ain, United Arab \\ Emirates; ${ }^{3}$ Ambulatory Healthcare \\ Services, SEHA, Abu Dhabi, United \\ Arab Emirates
}

Correspondence: Ahmed R Alsuwaidi Department of Pediatrics, College of Medicine and Health Sciences, United Arab Emirates University, Khalifa Bin Zayed Street, Al Ain, 17666,

United Arab Emirates

Tel +9 7I37I374II

Email alsuwaidia@uaeu.ac.ae
Introduction: Respiratory infections have significant effects on childhood asthma. Viral respiratory infections, such as rhinovirus and respiratory syncytial virus are likely to be important in the development and exacerbation of asthma. In this study, we investigated the nasopharyngeal colonization in children with asthma to determine the prevalence of pathogens and their contribution to respiratory symptoms and airway resistance during winter.

Methods: From December 2016 to March 2017, 50 nasopharyngeal specimens were collected from 18 patients (age, $5.0 \pm 1.1$ years) with asthma and 9 specimens from 9 control children (age, $4.9 \pm 1.0$ years). Samples were tested for 19 viruses and 7 bacteria, using multiplex real-time PCR. Respiratory disease markers included the Global Asthma Network Questionnaire, the Common-Cold Questionnaire, the Global Initiative for Asthma assessment of asthma control, and the airway resistance at $5 \mathrm{~Hz}$ by forced-oscillation technique.

Results: The most commonly isolated organisms in both groups (patients and controls) were Streptococcus pneumoniae, Haemophilus influenzae, and rhinovirus. Most patients had multiple isolates (median, 3.5; range, 1-5), which changed during the study period. Types of isolates were 4 bacteria (S. pneumoniae, H. influenzae, Bordetella pertussis, and Bordetella parapertussis) and 6 viruses (rhinovirus, enterovirus, metapneumovirus, adenovirus, coronaviruses, and parainfluenza viruses). Similar isolates, including influenza A-H3 virus and bocavirus, were detected in the controls. Of the 9 patients with "wheezing disturbing sleep $\geq 1$ per week", 6 had rhinovirus, 2 coronaviruses, and 1 no detectable viruses. Patients with mild common cold symptoms had significantly higher airway resistance at $5 \mathrm{~Hz} z$-score $(P=0.025)$.

Conclusion: Multiple respiratory pathogens were isolated from many patients with asthma, which appeared to contribute to disease symptoms and airway resistance. Minimizing children's exposure to respiratory pathogens might be beneficial, especially during winter.

Keywords: asthma, inhaled corticosteroids, respiratory pathogens, nasopharyngeal colonization, communicable diseases

\section{Introduction}

Viruses and bacteria contribute to the pathogenesis and natural history of childhood asthma. ${ }^{1}$ Respiratory syncytial virus (RSV) predominates in infants and toddlers, while human rhinovirus (hRV), influenza (Flu) viruses, parainfluenza virus (PIV), adenovirus $(\mathrm{AdV})$, coronavirus $(\mathrm{CoV})$, and human enterovirus $(\mathrm{hEV})$ are more prevalent in older children. ${ }^{2}$

It is common for children with asthma to develop respiratory symptoms, especially during winter. Many of their clinical findings, however, result from respiratory infections that require supportive care and minimizing exposure to respiratory pathogens. ${ }^{3,4}$ 
The prevailing practice, nevertheless, is escalating the use of short-acting $\beta$-agonists (SABAs), long-acting $\beta$-agonists (LABAs), inhaled corticosteroids (ICSs), and leukotriene receptor antagonist. These medications are expensive and may impose serious adverse events, especially in young children. ${ }^{5}$ Therefore, identifying and controlling triggers of asthma deserve further studies.

There are no studies from the United Arab Emirates (UAE) or surrounding countries that have evaluated respiratory infections or nasopharyngeal isolates in patients with asthma. However, few studies have addressed respiratory viral infections at community level. For example, in Saudi Arabia, most cases of RSV occur from November through March and some cases have been reported at other months of the year. ${ }^{6}$ In Kuwait, a study that has investigated the causative agents in $>1,000$ patients with lower respiratory tract infections using PCR revealed that RSV and hRV are the major isolates among hospitalized children from October to March. PIV-2 and human CoV were not detected in any of the patients' samples. ${ }^{7}$

Regular surveillance, especially during the winter is necessary if pathogens are to be identified with a view to possible prevention. This prospective, case-control pilot study aimed to estimate the prevalence of nasopharyngeal isolates in children with asthma during winter season and identify their clinical impact on respiratory symptoms and function. Its main objective was to address the importance of controlling respiratory pathogens in the treatment of childhood asthma.

\section{Materials and methods}

This study was conducted between December 2016 and March 2017 in the Pediatric Pulmonary Clinic at Tawam Hospital (Al Ain, UAE). It was approved by the Research Ethics Committee of the UAE University - College of Medicine and Health Sciences (ERH 2015323515 111). Written informed consent was obtained from the parents of all participants.

Children 3-6 years of age, with a diagnosis of asthma, were eligible to participate in the study. The clinical diagnosis of asthma was made by the pediatric pulmonologist, based on the Global Initiative for Asthma (GINA) criteria. ${ }^{8}$ Asthma staging ranged from mild to moderate, according to severity level and if the children required either ICS alone or in association with either LABA or montelukast. The study was explained to the parents of all eligible patients, and, if they agreed to the procedures, their children were enrolled in the study. The control group consisted of age-matched children without asthma, mainly relatives of our co-workers.
Immunization was up-to-date in all the studied participants. Children were excluded from the study if they had significant illnesses, such as chronic lung disease of prematurity, cystic fibrosis, congenital heart disease, immune deficiency, or upper airway anomaly. Demographic, medical, and vaccination data were reviewed. History of asthma symptoms was obtained using a modified global asthma network questionnaire. ${ }^{9}$ For the assessment of symptoms of viral infection, we used a validated Common Cold Questionnaire (CCQ). ${ }^{10}$ This questionnaire inquired about the presence of fever, chills, muscle pain, watery eyes, runny nose, sneezing, sore throat, cough, and chest pain during 2 days prior to specimen collection; each complaint was scored as none (0), mild (1), moderate (2), or severe (3). The GINA assessment of asthma control was used to assess the level of asthma control over the past 4 weeks. ${ }^{8}$ This instrument scored the presence (1) or absence ( 0 ) of each of the 4 clinical variables, day symptoms, night symptoms, reliever use, and exercise limitation. A score of zero indicated well-controlled asthma, 1-2 partly-controlled asthma, and 3-4 uncontrolled asthma.

Forced oscillation technique (FOT) was used to assess airway resistance using a commercial device (tremoFlo ${ }^{\mathrm{TM}}$ C-100, tremoFlo software, version 1.0.34 build 32; Thorasys Medical Systems, Montreal, QC, Canada), as previously described. ${ }^{11}$ Briefly, measurements were performed with the child sitting upright with the head in a neutral position, the cheeks supported, and the nose clipped. The child was instructed to breathe tidally through a mouthpiece. Data were collected over several seconds and the average of 3 acceptable measurements (coefficient of variation $\leq 15 \%$ ) was taken. Airway resistance at $5 \mathrm{~Hz}\left(\mathrm{R} 5\right.$, in $\left.\mathrm{cmH}_{2} \mathrm{O} . \mathrm{s} . \mathrm{L}^{-1}\right)$ was expressed as R5 $z$-score. ${ }^{11}$

\section{Sample collection and processing}

Multiple (1-3 and 4-6 weeks apart) nasopharyngeal specimens were collected from each patient between December 2016 and March 2017 (Tables 1, 2, S1, and S2). For controls, each participant had only 1 sample collected between January and March 2017 (Table 3). The specimens were stored at $-70^{\circ} \mathrm{C}$ until analysis, which was performed using the All-

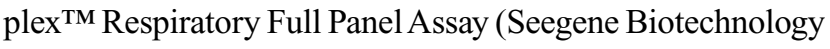
Inc., Seoul, Korea) as instructed by the manufacturer. ${ }^{12}$ The assay was composed of four panels and utilized a multiplex one-step real-time PCR to identify 16 viruses (with three influenza A subtypes) and seven bacteria. The viruses were influenza (Flu A, B, A-H1, A-H1pdm09, and A-H3), PIV (1-4), RSV (A and B), AdV, hEV, human metapneumovirus 
Table I Nasopharyngeal isolates, airway resistance (R5), "common cold" symptoms (CCQ), and GINA assessment of asthma control in the 18 patients with asthma (33 pathogens of 10 types); December 20I6-January 2017.

\begin{tabular}{|c|c|c|c|c|c|}
\hline $\begin{array}{l}\text { Patients, ID } \\
\text { number (sex, } \\
\text { age) }\end{array}$ & Isolates & CCQ score & GINA score & R5 z-score & Treatment modification \\
\hline I (M, 6.2 years) & HI, hRV & 0 & 3 & 0.59 & None \\
\hline 2 (F, 4.8 years) & SP & 2 & I & $\mathrm{I} .48$ & None \\
\hline 3 (M, 3.7 years) & hRV & 2 & 4 & Not done & Increased dose of ICS \\
\hline 4 (M, 4.8 years) & SP, HI, BPP, hRV & 10 & 4 & -0.14 & Salmeterol added to ICS \\
\hline 5 (M, 4.4 years) & SP, hRV, hEV, AdV & 0 & 4 & 1.40 & None \\
\hline 6 (M, 6.2 years) & SP, HI, CoV 229E, CoV NL63 & 3 & I & 1.36 & None \\
\hline 7 (M, 6.4 years) & None detected & 2 & 2 & 0.46 & None \\
\hline 8 (M, 4.9 years) & SP, CoV OC43 & 3 & 3 & 1.12 & None \\
\hline 9 (M, 6.5 years) & SP & II & 2 & 0.24 & None \\
\hline 10 (M, 6.4 years) & hRV & 0 & 4 & -0.06 & ICS started \\
\hline II (F, 4.9 years) & $\mathrm{SP}$ & 2 & Not done & 1.69 & None \\
\hline 12 (M, 4.4 years) & SP, HI, hRV & 7 & 4 & 1.54 & Montelukast added to ICS \\
\hline 13 (F, 4.2 years) & $\mathrm{HI}, \mathrm{hRV}$ & 16 & 3 & 0.20 & Salmeterol added to ICS \\
\hline 14 (M, 4.2 years) & SP, HI, hEV, PIV3 & 4 & I & 3.05 & None \\
\hline 15 (F, 4.9 years) & $\mathrm{SP}$ & 1 & Not done & 1.34 & None \\
\hline 16 (M, 3.6 years) & hRV & 0 & 4 & 3.55 & ICS started \\
\hline 17 (M, 6.1 years) & $\mathrm{HI}$ & 8 & 3 & -0.24 & ICS started \\
\hline 18 (M, 3.2 years) & Not done & Not done & Not done & Not done & None \\
\hline
\end{tabular}

Notes: The treatment modifications were based on clinical findings at the discretion of the primary physician (pediatric pulmonologist).

Abbreviations: AdV, adenovirus; BP, Bordetella pertussis; BPP, Bordetella parapertussis; CCQ, common cold questionnaire; CoV 229E, coronavirus 229E; CoV NL63, coronavirus NL63; CoV OC43, coronavirus OC43; F, female; GINA, Global Initiative of Asthma; hEV, human enterovirus; HI, Haemophilus influenzae; hRV, human rhinovirus; ICS, inhaled corticosteroid; M, male; SP, Streptococcus pneumoniae; PIVI, parainfluenza virus I; PIV3, parainfluenza virus 3; R5, airway resistance at 5 Hz

Table 2 CCQ score, GINA assessment of asthma control score, R5 z-score, nasopharyngeal isolates, and escalation of asthma prophylaxis

\begin{tabular}{lllllll}
\hline CCQ score & GINA score & N* & R5 z-score & Isolates & Treatment escalated N (\%) & P \\
\hline 0 & $0-I$ & 5 & $-0.48(I .22)$ & SP, HI, hRV, CoV 229E & $0(0)$ & $2(33)$ \\
& $\geq 2$ & 4 & $3.50(0.54)$ & SP, HI, hRV, hEV, AdV, PIVI & 0.4 \\
$I-7$ & $0-1$ & $I I$ & $I .42(I . I I)$ & SP, HI, hEV, PIV3, CoV 229E, CoV NL63, BP & $2(20)$ & $2(20)$ \\
& $\geq 2$ & 10 & $1.33(I .96)$ & SP, HI, hRV, CoV OC43, AdV, MPV & $2(50)$ & I.0 \\
$8-16$ & $0-1$ & 4 & $-0.43(I .76)$ & SP, HI, BP, PIVI & $2(50)$ & 1.0 \\
& $\geq 2$ & 4 & $0.03(0.90)$ & SP, HI, hRV, BPP &
\end{tabular}

Notes: $P$-values are Fisher's exact test. $* \mathrm{~N}$ indicates the number of patients with the stated $\mathrm{CCQ}$ score and GINA score.

Abbreviations: AdV, adenovirus; BP, Bordetella pertussis; BPP, Bordetella parapertussis; CCQ, common cold questionnaire; CoV 229E, coronavirus 229E; CoV NL63, coronavirus NL63; CoV OC43, coronavirus OC43; GINA, Global Initiative of Asthma; hEV, human enterovirus; HI, Haemophilus influenzae; hRV, human rhinovirus; MPV, metapneumovirus; SP, Streptococcus pneumoniae; PIVI, parainfluenza virus I; PIV3, parainfluenza virus 3; R5, airway resistance at $5 \mathrm{~Hz}$

(MPV), human bocavirus (hBoV), hRV, and CoV NL63, $\mathrm{CoV} 229 \mathrm{E}$, and CoV OC43. The bacteria were Streptococcus pneumoniae (SP), Haemophilus influenzae (HI), Mycoplasma pneumoniae, Chlamydophila pneumoniae, Legionella pneumophila, Bordetella pertussis (BP), and Bordetella parapertussis (BPP).

\section{Statistical analysis}

The data were analyzed with the SPSS statistical package (version 20). Descriptive statistics included the number and percentage, or the measured value of the observed variables, as appropriate. ANOVA was used to compare the R5 z-score on one hand, with the number of isolated pathogens, the GINA asthma control score, and the CCQ score on the other hand. The unpaired $t$-test was used to compare the R5 $z$-score between the children with asthma and the controls. For all tests, statistical significance was defined by a 2 -sided $P$-value $<0.05$.

\section{Results}

Fifty nasopharyngeal specimens were collected between December 2016 and March 2017 from 18 patients with 
Table 3 Nasopharyngeal isolates, airway resistance, and "common cold" symptoms in the 9 control children $(23$ isolates of 8 different types); December 2016-March 2017.

\begin{tabular}{lllll}
\hline $\begin{array}{l}\text { Children, ID } \\
\text { number (sex) }\end{array}$ & $\begin{array}{l}\text { Age } \\
\text { (years) }\end{array}$ & Isolates & $\begin{array}{l}\text { CCQ } \\
\text { score }\end{array}$ & $\begin{array}{l}\text { R5 } \\
\text { z-score }\end{array}$ \\
\hline I (F) & 3.5 & SP, HI, hRV, hBoV & 0 & $2.45^{\mathrm{a}}$ \\
2 (M) & 5.5 & SP, Flu A-H3 & 5 & 0.85 \\
3 (F) & 4.0 & SP, HI, hEV & 4 & -0.60 \\
4 (M) & 5.9 & SP, AdV & 0 & -0.82 \\
5 (M) & 5.1 & SP, HI, hRV & 0 & -1.99 \\
6 (F) & 5.5 & SP, Flu A-H3 & 6 & 2.45 \\
7 (M) & 5.1 & hRV, hEV & Not done & 0.25 \\
8 (M) & 4.2 & SP, hRV, hBoV, PIV4 & II & 2.09 \\
9 (F) & 3.3 & HI & Not done & 1.57 \\
\hline
\end{tabular}

Note: ${ }^{a}$ Child I was found subsequently to have symptoms of allergic rhinitis and mild night cough.

Abbreviations: AdV, adenovirus; $\mathrm{CCQ}$, common cold questionnaire; $\mathrm{F}$, female; Flu A-H3, influenza A virus-H3; hBoV, human bocavirus; hEV, human enterovirus; $\mathrm{HI}$, Haemophilus influenzae; hRV, human rhinovirus; M, male; SP, Streptococcus pneumoniae; $\mathrm{R} 5$, airway resistance at $5 \mathrm{~Hz}$

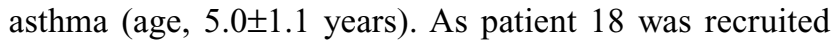
into the study only in February 2017 (Table 1), no data are available on him prior to that time, and his later results are included in Table S1. The results of studies performed between December 2016 and January 2017 are shown in Table 1, between January 2017 and February 2017 in Tables S1, and in March 2017 in Tables S2. Patients' responses to the Global Asthma Network Questionnaire are shown in Table S3. Only 6 patients used daily asthma prophylaxis (Table S3). In addition, 9 nasopharyngeal specimens were also collected from 9 control children who had no history of asthma (age, $4.9 \pm 1.0$ years); their results are shown in Table 3.

The prevalence of each isolate in patients and controls are shown in Figures 1 and S1. The most common organisms were SP, HI, and hRV for both groups.

Patients (December 2016-January 2017): Thirty-three pathogens (18 bacteria and 15 viruses) of 10 different types were isolated from 16 (94\%) of 17 patients with asthma; Patient 7 had no detectable isolate (Table 1). These organisms were SP (10 patients), HI (7 patients), BPP (1 patient), rhinovirus (7 patients), CoV (2 patients), hEV (2 patients), AdV (1 patient), and PIV-3 (1 patient). Four (23\%) patients had 4 pathogens, $1(6 \%)$ had 3 pathogens, $3(18 \%)$ had 2 pathogens, $8(47 \%)$ had 1 pathogen, and $1(6 \%)$ had none. Six $(75 \%)$ of 8 patients with rhinovirus had a treatment modification, such as starting ICS (3 patients), increased ICS dosing (2 patients), or adding montelukast or salmeterol to the ICS (3 patients), Table 1.

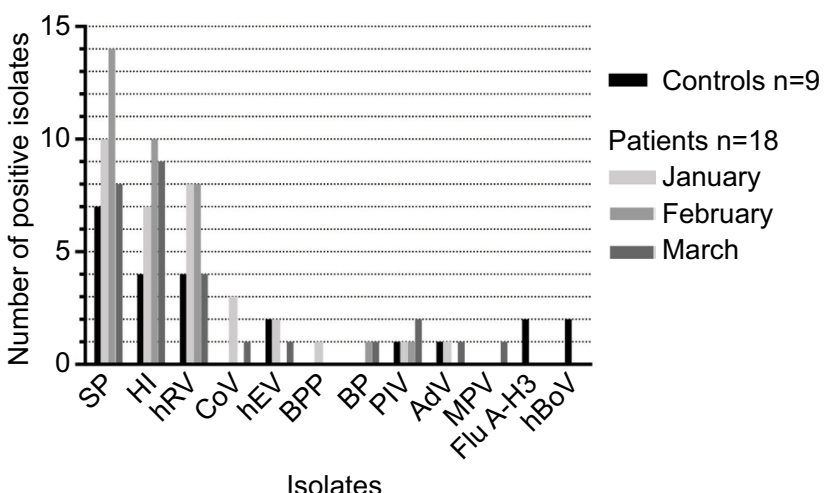

Figure I Nasopharyngeal pathogens isolated from the 18 patients with asthma and the 9 healthy children during the studied winter periods.

Abbreviations: AdV, adenovirus; BP, Bordetella pertussis; BPP, Bordetella parapertussis; CoV, coronavirus; Flu $\mathrm{A}-\mathrm{H} 3$, influenza $\mathrm{A}$ virus- $\mathrm{H} 3$; $\mathrm{hBoV}$, human bocavirus; hEV, human enterovirus; hRV, human rhinovirus; HI, Haemophilus influenzae; PIV, parainfluenza virus; SP, Streptococcus pneumoniae.

Nine (52\%) patients had mild common cold symptoms (CCQ scores ranged from 1 to 7 of a maximum score of 27), 4 (24\%) had moderate symptoms (CCQ scores ranged from 8 to 16 ), and 4 (24\%) had no symptoms (CCQ score $=0$ ), Table 1. Isolates from patients with CCQ score $\geq 7$ included SP (Patients 4, 9, and 12), HI (Patients 4, 12, and 17), BPP (Patient 4), and hRV (Patients 4, 12, and 13).

Twelve (80\%) of 15 patients had GINA assessment of asthma control score of $\geq 2$ (maximum score, 4 ; Table 1 ). The $\mathrm{R} 5 z$-score (airway resistance) was not significantly different when compared among children with different number of pathogens isolated ( $P=0.2$, ANOVA). Similarly, the R5 $z$-score was not significantly different among children with different CCQ scores ( $P=0.1$, ANOVA) or GINA control scores $(P=0.5$, ANOVA).

Patients (February-March 2017): Isolate profiles changed in the majority of patients (Tables S1 and S2). For example, Patient 3 acquired BP and Patient 6 rhinovirus (Table S1). Many of previously detected viruses were not present on the subsequent testing; eg, Patients 6 and 8 lost their colonizations with $\mathrm{CoV}$ (Table S1). Different strains of PIV also appeared in March 2017 (PIV1 in Patient 11, and PIV4 in Patient 12; Table S2); while the strain detected in December-January was PIV3 (Patient 14, Table 1).

It is worth noting that BP and BPP were detected during the entire study period. The 2 patients with BP (Patients 2 and 3, Tables S1 and S2) had increased ICS dosing.

Table 2 shows the pathogens isolated from patients sorted by varying degrees of CCQ and GINA assessment of asthma control scores. The 4 patients with CCQ scores $=0$ and GINA 
assessment of asthma control scores $\geq 2$ had increased airway resistance (high mean R5 $z$-scores), suggesting poor asthma control. However, only 2 of these patients had treatment escalation.

The impact of common cold symptoms on airway resistance is shown in Figure 2A. Patients with a CCQ score of $1-7$ had significantly higher R5 $z$-score $(P=0.025)$.

Nine of the 18 patients had "wheezing disturbing sleep $\geq 1$ per week" (Table S3). Six of these patients had rhinovirus, 2 had CoV, and 1 had severe atopy (Patient 18), Table 1.

A
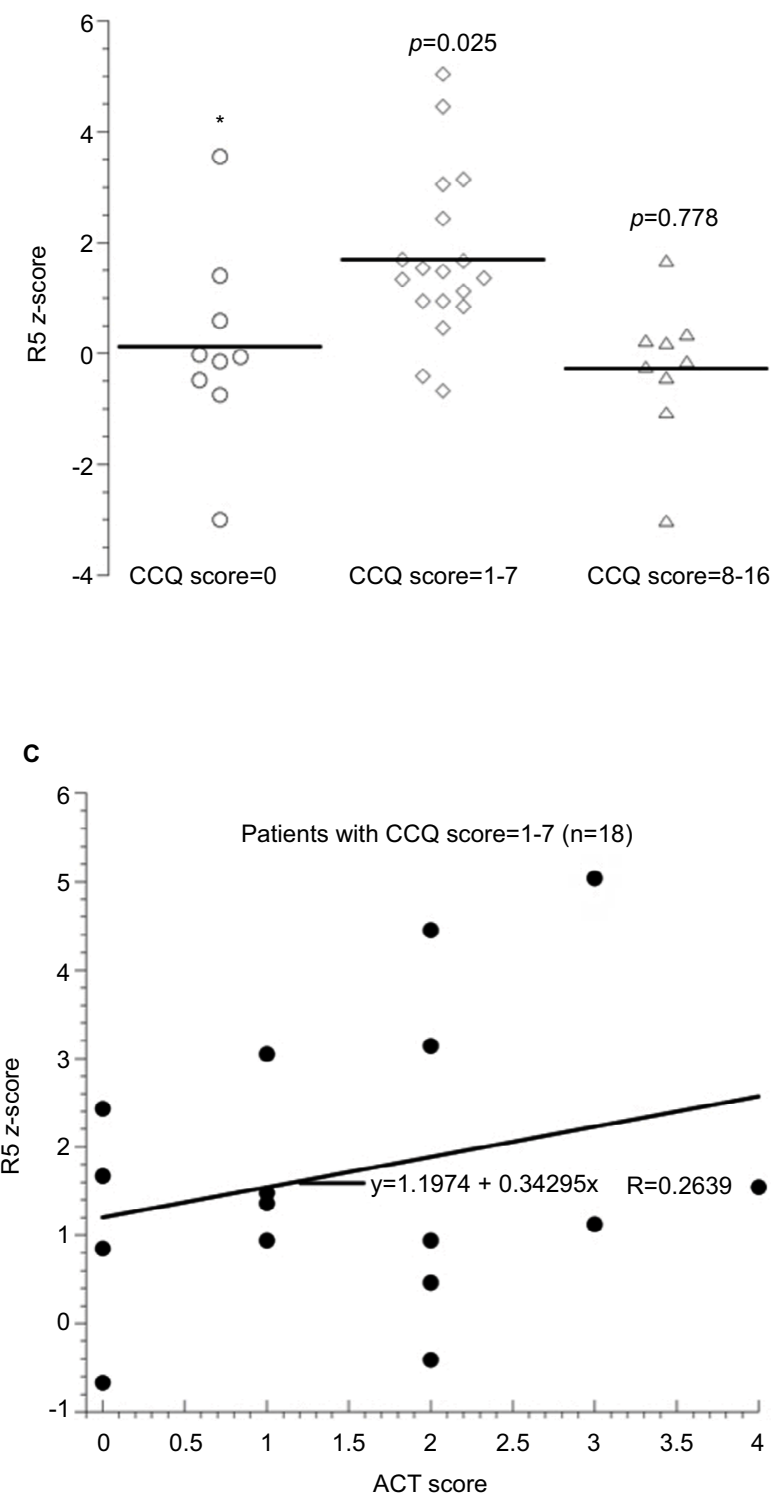

Treatment modifications: The treatment modifications, based on clinical findings, were made at the discretion of their pediatric pulmonologist and are detailed in Table 1. Many patients were already on controller medications prior to the study as shown in Table S3.

Controls (December 2016-March 2017): Twenty-three pathogens isolated from the control children: SP (7 children), HI (4 children), rhinovirus (4 children), Flu A-H3 (2 children), enterovirus ( 2 children), hBoV ( 2 children), PIV4 (1 child) and AdV (1 child), Table 3 and Figure 1. Two (22\%)

B

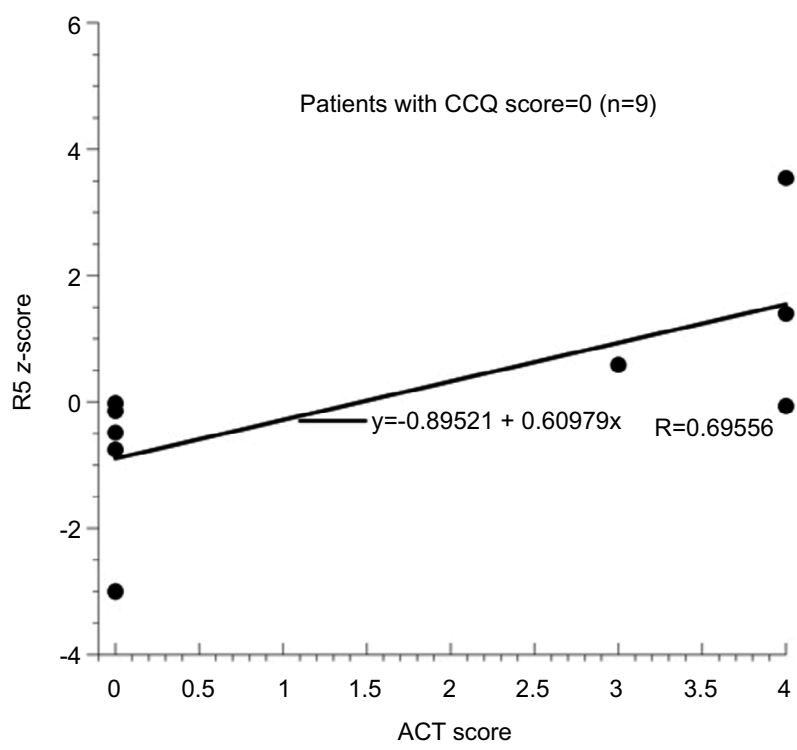

D

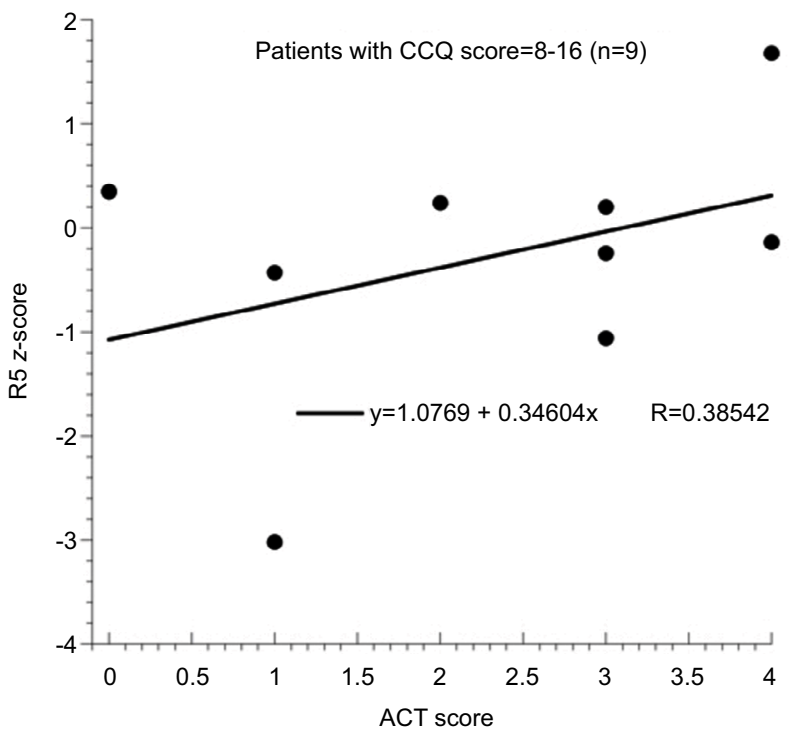

Figure 2 The horizontal lines are mean values. The $P$-values are Mann-Whitney (2-tailed) between CCQ score $=0$ and the other groups. Kruskal-Wallis test that compared 3 CCQ groups revealed an asymptotic significance (2-tailed) of 0.013. Panel (A): R5 z-scores in the patients with asthma as function of CCQ score. Panels (B-D): R5 z-scores as function of Global Initiative of Asthma assessment of asthma control score in the patients with asthma grouped by their CCQ score.

Abbreviations: ACT, asthma control test; CCQ, Common Cold Questionnaire; R5, airway resistance at $5 \mathrm{~Hz}$. 
children had 4 pathogens, $2(22 \%)$ had 3 pathogens, $4(45 \%)$ had 2 pathogens, and $1(11 \%)$ had 1 pathogen. The results of their airway resistance and CCQ scores are detailed in Table 3 . The R5 $z$-score (airway resistance) was not significantly different between children with asthma and controls $(P=0.8$, unpaired $t$-test).

\section{Discussion}

The nasopharynx is a reservoir for pathogens associated with respiratory diseases, such as asthma. Airway microbiome studies have shown that bacteria may play a substantial role in the onset, evolution, and severity of asthma. ${ }^{13}$

This study was conducted to test the hypothesis that nasopharyngeal colonizations with community-acquired pathogens have an adverse impact on the natural history of asthma in young children. The results show that the majority of patients with asthma had several viral pathogens, which contributed to symptoms and airway resistance (Tables 1 and 2). The clinical impact of the respiratory pathogens on asthma control is shown in Table 1. Patients 2 and 3 had increased CCQ scores in association with colonizations with HI and $\mathrm{BP}$ on the second sampling. The increased airway resistance in Patient 5 on the second sample collection could be due to colonization with HI or adverse events of prior AdV. Similarly, the increased airway resistance in Patient 8 could be due to prior $\mathrm{CoV}$ OC43. The high airway resistance in Patient 14 could be due to PIV-3. As the course and severity of asthma are also related to the role of many environmental factors (such as air pollution, humidity, and smoking), medication adherence, and poor inhaler technique, it is not totally unexpected that the role of respiratory pathogens cannot be considered in isolation and cannot be solely responsible for asthma control. With respect to the controls (Table 3), Children 1 and 6 both had high airway resistance associated with multiple colonizations. Child 1 was found subsequently to have symptoms of allergic rhinitis and mild night cough.

The 2 patients who were found to have pertussis had increased symptoms, possibly falsely attributed to worsening asthma control, leading to inappropriate escalation of their medications before the infection was diagnosed (Tables S1 and S2). In addition, patients with asthma are at increased risk for pertussis infection. This was highlighted during the 2004 pertussis outbreak in MN, USA where the population attributable risk percentage of asthma for risk of pertussis was calculated to be $17 \% .{ }^{14}$ Consistently, humoral immunoreaction to BP could be suppressed in patients with asthma. ${ }^{15}$ Therefore, targeting patients with asthma for pertussis surveillance and vaccination as a selective high-risk group might be an appropriate strategy.

Children with asthma may have an increased risk of pneumonia. ${ }^{16}$ This might be facilitated by their use of ICS, as these medications also inhibit mucosal immune responses, thus encouraging colonization with organisms. ${ }^{5}$

In children with no common cold symptoms, $33 \%$ had asthma prophylaxis therapy escalated in association with an elevated GINA assessment of asthma control score and increased airway resistance (probably justifiably; Table 2). In those with mild common cold symptoms, $20 \%$ had asthma prophylaxis therapy increased in association with increased airway resistance, although 50\% had low GINA assessment of asthma control score. In those with more severe common cold symptoms, $50 \%$ had asthma prophylaxis therapy escalated, regardless of the GINA assessment of asthma control score and without increase in airway resistance (probably intensification triggered by the severity of cold symptoms instead of asthma score or airway resistance; probably not justified here), Table 2 .

In the northern hemisphere, most asthma-related emergency department visits are higher in September than other months. In late fall, there is often a "second wave" with fluctuations throughout winter probably coinciding with rhinovirus episodes. ${ }^{17,18}$ Symptomatic rhinovirus infections are found to be an important contributor to asthma exacerbations in children. ${ }^{19}$ In this study, rhinovirus (hRV) was detected in the majority of patients (Figure 1). Future studies are needed to address important variables relevant to this organism, such as serotypes (especially HRV-16), upper vs lower respiratory colonization, and host susceptibility (eg, variability in expression of intercellular adhesion molecule-1). ${ }^{2}$

Airway inflammation has been reported in infections with Flu viruses, which are well known to induce severe exacerbation in adults. ${ }^{4} M$. pneumoniae and C. pneumoniae, on the other hand, seem to be involved in asthma persistence. ${ }^{1,4}$ The atypical bacteria $C$. pneumoniae and $M$. pneumoniae were not detected in our studied population. These pathogens may be more important in adults with chronic asthma. Similarly, RSV and MPV were not detected in the patients. This finding could be due to the small sample size of the study or to the regional epidemic pattern of these pathogens. Thus, surveillances that cover the entire year are necessary.

In 1 study, children ( 3 months to 16 years of age) with asthma exacerbation had a high prevalence of respiratory pathogens that included RSV, hRV, $M$. pneumoniae, and $C$. pneumoniae. Most hospitalizations were associated with 
seasonal hRV and $\mathrm{RSV}^{4} \mathrm{MPV}$ and $\mathrm{hBoV}$ were previously reported in children with asthma exacerbation. ${ }^{12,13,20,21}$ In this current study, hBoV was detected in 1 healthy child (Table 3 ) and MPV in 1 patient (Table S2).

It is worth noting that $\mathrm{R} 5 z$-score in patients with a CCQ score $\geq 8$ was similar to those with CCQ score $=0$ (Figure 2A). In addition, R5 $z$-scores correlated best with GINA assessment of asthma control scores in patients with CCQ score $=0 \quad(R>0.695)$ (Figure 2B-D). These findings reflect a limitation in using FOT in patients with significant upper respiratory symptoms, which have been shown to influence FOT resistance measurements.

The study finding supports the need for strategies that limit children's exposure to respiratory viruses and bacteria, especially those with poorly controlled disease. Specific measures that have been suggested to minimize recurrent infections in children with asthma include hand hygiene, a healthy balanced diet, active probiotic supplements, and the immunostimulant OM-85. ${ }^{22}$ Further studies, however, are needed to investigate whether reducing exposure to pathogens would improve asthma control. In addition, the role of other environmental factors (such as air pollution, humidity, and smoking), medication adherence, and poor inhaler technique has to be taken into consideration in future studies.

\section{Conclusion}

The majority of patients with asthma had viral and bacterial pathogens contributing to their disease. Regular surveillance could play a role in asthma care, especially in those with poorly controlled disease. Effective strategies to minimize exposure to respiratory pathogens, such as hand hygiene should be incorporated in childhood asthma guidelines. Such approach would emphasize the importance of environmental control measures rather than relying solely on escalating asthma drug therapy with its potential toxicity. Further studies are needed to evaluate whether strategies that minimize children's exposure to pathogens would improve asthma control.

\section{Acknowledgments}

The authors are grateful to all participating children and their parents. The contribution of Mrs Sania M Al-Hamad toward data collection is greatly appreciated. The study was funded by a grant from the College of Medicine and Health Sciences, UAE University (31M252). The funding body had no role in the design of the study, collection, analysis, and interpretation of data, or in writing the manuscript.

\section{Author contributions}

ARA conceived the study, participated in its design and coordination, and drafted the manuscript. AMA, AA, and GA recruited participants and collected clinical data. JG and SMK coordinated and performed PCR experiments. HN and AKS participated in the data analysis and manuscript preparation. All authors contributed toward data analysis, drafting and critically revising the paper, gave final approval of the version to be published, and agree to be accountable for all aspects of the work.

\section{Disclosure}

The authors report no conflicts of interest in this work.

\section{References}

1. Papadopoulos NG, Christodoulou I, Rohde G, et al. Viruses and bacteria in acute asthma exacerbations--a GA ${ }^{2}$ LEN-DARE systematic review. Allergy. 2011;66(4):458-468.

2. Tovey ER, Stelzer-Braid S, Toelle BG, et al. Rhinoviruses significantly affect day-to-day respiratory symptoms of children with asthma. J Allergy Clin Immunol. 2015;135(3):663-669.

3. Halmø Hürdum S, Zhang G, Khoo SK, et al. Recurrent rhinovirus detections in children following a rhinovirus-induced wheezing exacerbation: A retrospective study. Int J Pediatr Child Health. 2015;3(1):10-18.

4. Maffey AF, Barrero PR, Venialgo C, et al. Viruses and atypical bacteria associated with asthma exacerbations in hospitalized children. Pediatr Pulmonol. 2010;45(6):619-625.

5. Zhang L, Prietsch SO, Mendes AP, et al. Inhaled corticosteroids increase the risk of oropharyngeal colonization by Streptococcus pneumoniae in children with asthma. Respirology. 2013;18(2):272-277.

6. Al-Alaiyan S, Pollack P, Notario GF. Safety and pharmacokinetics of extended use of palivizumab in Saudi Arabian infants and children. Drugs Context. 2015;4: pii: 212270.

7. Khadadah M, Essa S, Higazi Z, Behbehani N, Al-Nakib W. Respiratory syncytial virus and human rhinoviruses are the major causes of severe lower respiratory tract infections in Kuwait. J Med Virol. 2010;82(8): 1462-1467.

8. GINA. Global Initiative for Asthma, Global Strategy for Asthma Management and Prevention; 2015. Available from: https://www.ginasthma. org. Accessed on October 24, 2016.

9. Global Asthma Network. Available from: http://www.globalasthmanetwork.org/surveillance/manual/study6.php. Accessed October 24, 2016.

10. Powell H, Smart J, Wood LG. Validity of the common cold questionnaire (CCQ) in asthma exacerbations. PLoS One. 2008; 19(3):e1802.

11. Alblooshi A, Alkalbani A, Narchi H, et al. Respiratory function in healthy Emirati children using forced oscillations. Pediatr Pulmonol. 2018;53(7):936-941.

12. Park S, Oh KC, Kim KS, et al. Role of Atypical Pathogens and the Antibiotic Prescription Pattern in Acute Bronchitis: A Multicenter Study in Korea. J Korean Med Sci. 2015;30(10):1446-1452.

13. Pérez-Losada M, Alamri L, Crandall KA, Freishtat RJ. Nasopharyngeal Microbiome Diversity Changes over Time in Children with Asthma. PLoS One. 2017;12(1):e0170543.

14. Capili CR, Hettinger A, Rigelman-Hedberg N, et al. Increased risk of pertussis in patients with asthma. J Allergy Clin Immunol. 2012;129(4):957-963.

15. Nakamura A, Iwashima Y, Takakuwa O, Sato S. Sensitivity to bordetella pertussis in asthmatic patients. Eur Respir J. 2011;38:p2515.

16. Martin M, Shaw D. Effect of inhaled corticosteroids on the microbiology of the respiratory tract. Respirology. 2013;18(2):201-202. 
17. Larsen K, Zhu J, Feldman LY, et al. The Annual September Peak in Asthma Exacerbation Rates. Still a Reality? Ann Am Thorac Soc. 2016;13(2):231-239.

18. Cohen HA, Blau H, Hoshen M, Batat E, Balicer RD. Seasonality of asthma: a retrospective population study. Pediatrics. 2014;133(4):e923-e932.

19. Khetsuriani N, Kazerouni NN, Erdman DD, et al. Prevalence of viral respiratory tract infections in children with asthma. J Allergy Clin Immunol. 2007;119(2):314-321.
20. Jartti T, van den Hoogen B, Garofalo RP, Osterhaus AD, Ruuskanen O. Metapneumovirus and acute wheezing in children. Lancet. 2002; 360(9343):1393-1394.

21. Allander T, Jartti T, Gupta S, et al. Human bocavirus and acute wheezing in children. Clin Infect Dis. 2007;44(7):904-910.

22. Ahanchian H, Jones CM, Chen Y-Sheng, Sly PD. Respiratory viral infections in children with asthma: do they matter and can we prevent them? BMC Pediatr. 2012;12:147. 


\section{Supplementary materials}

A

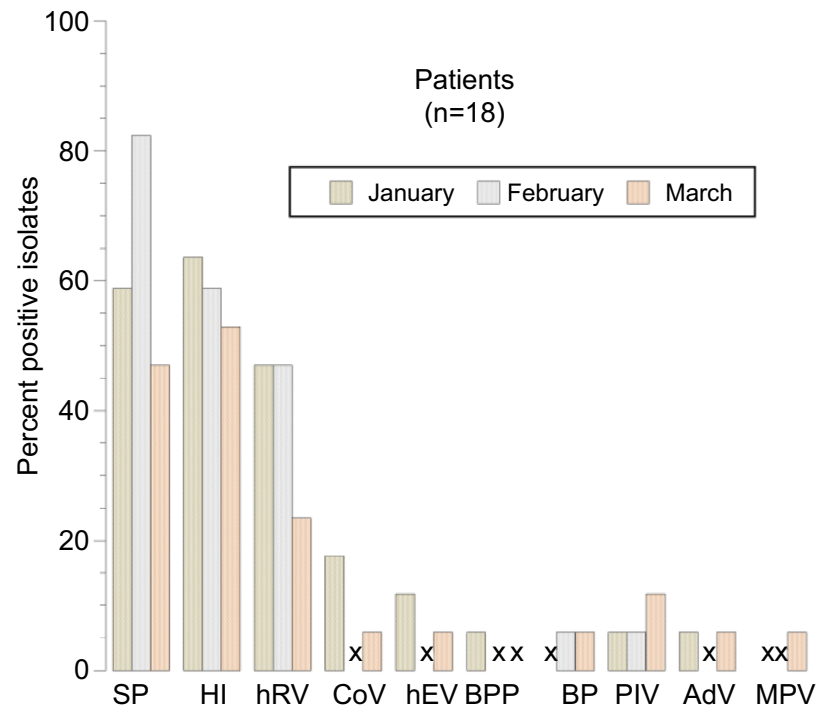

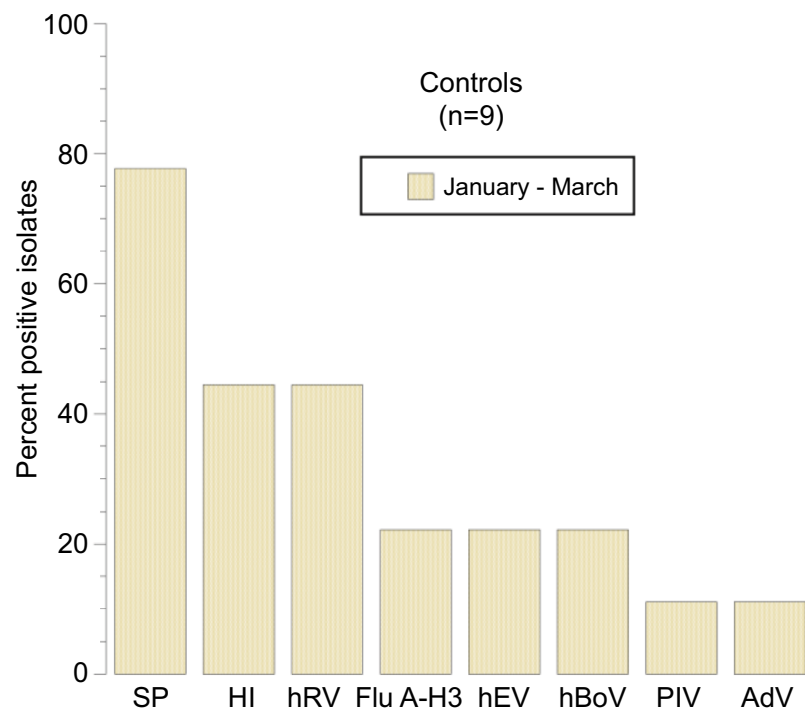

Figure SI Percent positive nasopharyngeal pathogens isolated from the 18 patients with asthma $(\mathbf{A})$ and the 9 healthy children (B) during the studied winter periods. Note: "x", not detected.

Abbreviations: AdV, adenovirus; BP, Bordetella pertussis; BPP, Bordetella parapertussis; CoV coronavirus; Flu A-H3, influenza A virus-H3; hBoV, human bocavirus; hEV, human enterovirus; HI, Haemophilus influenzae; hRV, human rhinovirus; PIVI, parainfluenza virus I; PIV3, parainfluenza virus 3; SP, Streptococcus pneumoniae.

Table SI Nasopharyngeal isolates, airway resistance (R5), "common cold” symptoms (CCQ), and GINA score in the I8 patients with asthma

\begin{tabular}{|c|c|c|c|c|}
\hline \multirow{2}{*}{$\begin{array}{l}\text { Patients, ID } \\
\text { number (sex, age) }\end{array}$} & \multicolumn{4}{|c|}{ February 2017 (34 pathogens of five different types) } \\
\hline & Isolates & CCQ scores & GINA scores & R5 z-scores \\
\hline I (M, 6.2 years) & SP, HI, PIVI & 0 & 3 & Not successful \\
\hline $2(\mathrm{~F}, 4.8$ years) & $\mathrm{SP}, \mathrm{HI}$ & 7 & I & 0.94 \\
\hline 3 (M, 3.7 years) & $\mathrm{HI}, \mathrm{BP}$ & 5 & 0 & 1.67 \\
\hline 4 (M, 4.8 years) & $\mathrm{HI}, \mathrm{hRV}$ & 0 & 0 & -0.02 \\
\hline 5 (M, 4.4 years) & SP, HI, hRV & 4 & 2 & 4.45 \\
\hline $6(\mathrm{M}, 6.2$ years $)$ & SP, HI, hRV & 4 & 0 & Not done \\
\hline 7 (M, 6.4 years) & SP, HI, hRV & 2 & 1 & Not done \\
\hline 8 (M, 4.9 years) & $\mathrm{SP}$ & I & 2 & 3.14 \\
\hline 9 (M, 6.5 years) & $\mathrm{SP}$ & 9 & 3 & -1.06 \\
\hline 10 (M, 6.4 years) & Not done & Not done & Not done & Not done \\
\hline II (F, 4.9 years) & $\mathrm{SP}$ & 0 & Not done & Not done \\
\hline 12 (M, 4.4 years) & $\mathrm{SP}, \mathrm{HI}$ & 0 & 0 & -0.14 \\
\hline 13 (F, 4.2 years) & SP, hRV & 0 & 3 & Not done \\
\hline 14 (M, 4.2 years) & SP, hRV & 7 & 2 & 0.94 \\
\hline 15 (F, 4.9 years) & SP, HI, hRV & 5 & 0 & Not done \\
\hline 16 (M, 3.6 years) & hRV & 0 & 0 & -3.00 \\
\hline 17 (M, 6.I years) & $\mathrm{SP}$ & 9 & 0 & Not done \\
\hline 18 (M, 3.2 years) & SP, HI & 0 & Not done & 5.29 \\
\hline
\end{tabular}

Note: Patients 2 and 3 had treatment modifications, which included increased inhaled corticosteroid dosing.

Abbreviations: AdV, adenovirus; BP, Bordetella pertussis; BPP, Bordetella parapertussis; CCQ, common cold questionnaire; CoV 229E, coronavirus 229E; CoV NL63, coronavirus NL63; CoV OC43, coronavirus OC43; F, female; GINA, Global Initiative of Asthma; hEV, human enterovirus; HI, Haemophilus influenzae; hRV, human rhinovirus; M, male; SP, Streptococcus pneumoniae; PIVI, parainfluenza virus I; PIV3, parainfluenza virus 3; R5, airway resistance at $5 \mathrm{~Hz}$. 
Table S2 Nasopharyngeal isolates, airway resistance (R5), "common cold" symptoms (CCQ), and GINA in the 18 patients with asthma

\begin{tabular}{|c|c|c|c|c|}
\hline \multirow{2}{*}{$\begin{array}{l}\text { Patients, ID } \\
\text { number (sex, age) }\end{array}$} & \multicolumn{4}{|c|}{ March 2017 (28 pathogens of 9 different types) } \\
\hline & Isolates & CCQ scores & GINA scores & R5 z-scores \\
\hline I (M, 6.2 years) & Not done & Not done & Not done & Not done \\
\hline $2(\mathrm{~F}, 4.8$ years) & $\mathrm{SP}, \mathrm{BP}$ & 9 & I & -3.02 \\
\hline 3 (M, 3.7 years) & CoV $229 E$ & 0 & 0 & -0.75 \\
\hline 4 (M, 4.8 years) & None detected & 0 & 0 & -0.48 \\
\hline 5 (M, 4.4 years) & SP, HI, hRV & 5 & 3 & 5.04 \\
\hline $6(\mathrm{M}, 6.2$ years $)$ & SP, HI, hRV & 4 & 0 & 2.43 \\
\hline 7 (M, 6.4 years) & SP, HI, HEV, Adv & I & 2 & -0.41 \\
\hline 8 (M, 4.9 years) & SP, HI, MPV & 4 & 2 & Not done \\
\hline 9 (M, 6.5 years) & $\mathrm{SP}, \mathrm{HI}$ & 3 & 0 & 0.85 \\
\hline 10 (M, 6.4 years) & None detected & Not done & Not done & Not done \\
\hline II (F, 4.9 years) & SP, PIVI & 8 & I & -0.43 \\
\hline 12 (M, 4.4 years) & HI, hRV, PIV4 & 9 & I & Not done \\
\hline I 3 (F, 4.2 years) & None detected & Not done & Not done & Not done \\
\hline 14 (M, 4.2 years) & $\mathrm{SP}, \mathrm{HI}$ & 13 & 4 & 1.68 \\
\hline 15 (F, 4.9 years) & $\mathrm{HI}, \mathrm{hRV}$ & 3 & 0 & -0.67 \\
\hline 16 (M, 3.6 years) & None detected & Not done & Not done & Not done \\
\hline 17 (M, 6.I years) & $\mathrm{HI}$ & 8 & 0 & 0.35 \\
\hline 18 (M, 3.2 years) & Not done & Not done & Not done & Not done \\
\hline
\end{tabular}

Note: Patient 2 had increased inhaled corticosteroid dosing.

Abbreviations: AdV, adenovirus; BP, Bordetella pertussis; BPP, Bordetella parapertussis; CCQ, common cold questionnaire; CoV 229E, coronavirus 229E; CoV NL63, coronavirus NL63; CoV OC43, coronavirus OC43; F, female; GINA, Global Initiative of Asthma; hEV, human enterovirus; HI, Haemophilus influenzae; hRV, human rhinovirus; M, male; SP, Streptococcus pneumoniae; PIVI, parainfluenza virus I; PIV3, parainfluenza virus 3; R5, airway resistance at $5 \mathrm{~Hz}$.

Table S3 Responses to the Global Asthma Network Questionnaire (based on symptoms in the past 12 months) in the 18 patients with asthma

\begin{tabular}{|c|c|c|c|c|c|c|c|c|c|c|c|}
\hline $\begin{array}{l}\text { Patients } \\
\text { ID }\end{array}$ & $\begin{array}{l}\text { Number of } \\
\text { wheezing } \\
\text { episodes }\end{array}$ & $\begin{array}{l}\text { Wheezing } \\
\text { disturbing } \\
\text { night sleep }\end{array}$ & $\begin{array}{l}\text { Wheezing } \\
\text { limiting } \\
\text { speech }\end{array}$ & $\begin{array}{l}\text { Emergency } \\
\text { wheezing }^{\mathrm{a}}\end{array}$ & $\begin{array}{l}\text { Days } \\
\text { missed } \\
\text { school }\end{array}$ & $\begin{array}{l}\text { Exercise- } \\
\text { induced } \\
\text { wheezing }\end{array}$ & Rhinitis & Eczema & $\begin{array}{l}\text { Chest } \\
\text { infection } \\
\text { in infancy }\end{array}$ & $\begin{array}{l}\text { Use of } \\
\text { SABA }\end{array}$ & $\begin{array}{l}\text { Use of } \\
\text { LABA/ } \\
\text { ICS }\end{array}$ \\
\hline 1 & $?$ & $?$ & $?$ & $>2$ & 0 & No & Yes & Yes & $\geq 6$ & Every day & Every day \\
\hline 2 & $4-12$ & Never & No & 2 & 0 & No & No & No & $?$ & As needed & $?$ \\
\hline 3 & $I-3$ & $\geq \mathrm{I} / \mathrm{wk}$ & no & I & & No & Yes & Yes & 1 & As needed & $?$ \\
\hline 4 & $>12$ & $\geq \mathrm{I} / \mathrm{wk}$ & Yes & I & $4-12$ & Yes & Yes & No & $2-5$ & $?$ & $?$ \\
\hline 5 & $\mathrm{I}-3$ & $\geq \mathrm{I} / \mathrm{wk}$ & No & I & $4-12$ & Yes & No & Yes & 0 & As needed & Courses \\
\hline 6 & $4-12$ & $\geq \mathrm{I} / \mathrm{wk}$ & Yes & I & 0 & Yes & Yes & No & 1 & $?$ & $?$ \\
\hline 7 & $?$ & $?$ & $?$ & 0 & 0 & No & Yes & Yes & 0 & Courses & Every day \\
\hline 8 & $4-12$ & $\geq \mathrm{I} / \mathrm{wk}$ & No & 2 & $>12$ & No & Yes & Yes & $2-5$ & As needed & Every day \\
\hline 9 & $I-3$ & $<\mathrm{l} / \mathrm{wk}$ & No & 2 & $1-3$ & No & Yes & No & $2-5$ & Courses & $?$ \\
\hline 10 & $I-3$ & $\geq \mathrm{I} / \mathrm{wk}$ & No & I & 0 & Yes & Yes & No & 1 & As needed & $?$ \\
\hline II & $I-3$ & $<\mathrm{l} / \mathrm{wk}$ & No & I & 0 & Yes & Yes & Yes & 1 & As needed & Courses \\
\hline 12 & $I-3$ & $\geq \mathrm{l} / \mathrm{wk}$ & No & I & $\mathrm{I}-3$ & Yes & Yes & Yes & 1 & Courses & $?$ \\
\hline 13 & $?$ & $?$ & $?$ & 2 & $I-3$ & Yes & Yes & No & $2-5$ & $?$ & $?$ \\
\hline 14 & $I-3$ & $<\mathrm{l} / \mathrm{wk}$ & No & 2 & 0 & No & Yes & No & 0 & $?$ & Every day \\
\hline 15 & $?$ & $?$ & $?$ & 0 & 0 & Yes & Yes & No & 0 & As needed & As needed \\
\hline 16 & $4-12$ & $\geq \mathrm{I} / \mathrm{wk}$ & No & I & $4-12$ & Yes & No & Yes & 0 & As needed & Every day \\
\hline 17 & $\mathrm{I}-3$ & $<\mathrm{l} / \mathrm{wk}$ & No & I & $4-12$ & Yes & Yes & No & 1 & As needed & Every day \\
\hline 18 & $4-12$ & $\geq \mathrm{I} / \mathrm{wk}$ & No & 0 & 0 & $?$ & $?$ & $?$ & $?$ & $?$ & $?$ \\
\hline
\end{tabular}

Note: "Wheezing requiring urgent doctor or emergency department visit or hospitalization; "?", skipped responses.

Abbreviations: ICS, inhaled corticosteroid; LABA, long acting $\beta$-agonist; SABA, short acting $\beta$-agonist; wk, week. 
Journal of Asthma and Allergy

The Journal of Asthma and Allergy is an international, peer-reviewed open access journal publishing original research, reports, editorials and commentaries on the following topics: Asthma; Pulmonary physiology; Asthma related clinical health; Clinical immunology and the immunological basis of disease; Pharmacological interventions and new therapies. This journal is included in PubMed. The manuscript management system is completely online and includes a very quick and fair peer-review system, which is all easy to use. Visit http://www. dovepress.com/testimonials.php to read real quotes from published authors.

Submit your manuscript here: https://www.dovepress.com/journal-of-asthma-and-allergy-journal 